\title{
Synthesis of 3-(4-aminophenyl) cyclopropane-1, 1,2,2-tetracarbonitrile
}

\author{
Shanshan Hou, Yuanzhang Zhou, Wei Lu, Jiaqian Han, Ziwei Zhang \& Shan Xu \\ School of Pharmacy, Jiangxi Science \& Technology Normal University, Nanchang 330013, China \\ Corresponding author: Shan $\mathrm{Xu}$
}

\begin{abstract}
: 3-(4-aminophenyl) cyclopropane-1, 1, 2, 2-tetracarbonitrile (1) is an important intermediate which used to synthesize NVP-BEZ-235 derivative. In this work, a rapid synthetic method for compound 1 was established. The 3-(4-aminophenyl) cyclopropane-1, 1, 2, 2-tetracarbonitrile was synthesized from the commercially available 4-nitrobenzaldehyde through three steps. The structure was confirmed by MS and ${ }^{1}$ HNMR. Furthermore, the synthetic method was optimized. The total yield of the three steps was $65.25 \%$ (caculated from malononitrile).
\end{abstract}

KEYWORD: 2-(4-nitrobenzylidene)malononitrile; 3-(4-nitrophenyl)cyclopropane-1,1,2,2-tetracarbonitrile; 3(4-aminophenyl)cyclopropane-1,1,2,2-tetracarbonitrile; Synthesis

\section{INTRODUCTION}

Cancer is a major public health problem in the world, which caused by the disorders of cell proliferation mechanism $^{[1]}$. Developing an efficiently and safety method to treatment the malignancies has become a hot pot in nowadays. In recent years, many small molecule anticancer drugs had been reported ${ }^{[2-4]}$, such as NVP-BEZ-235, 2-methyl-2-(4-(3-methyl-2oxo-8-(quinolin-3-yl)-2, 3-dihydro-1H-imidazo [4,5c] quinolin-1-yl)phenyl) propanenitrile (3), 1-(4- (3methyl-2-oxo-8-(quinolin-3-yl)-2, 3-dihydro-1Himidazo[4,5-c]quinolin-1-yl)phenyl) cyclopropanecarbonitrile(4) ${ }^{[5-6]}$. 3- (4-aminop henyl) cyclopropane -1, 1, 2, 2 - tetracarbonitrile is the key intermediate and has a wide range of applications in the pharmaceutical and chemical fields. Some moleculers are designed and synthesized basing on 3- (4aminop henyl) cyclopropane -1,1,2,2tetracarbonitrile. Such as 3-(4-nitrophenyl)-2,2dicyanocyclopropane-1,1-dicarboxylic acid diethyl ester(5) ${ }^{[7]}$. 2-Acetyl-2-methyl-3-(4-nitro-phenyl)cyclopropane-1,1-dicarbonitrile(6) ${ }^{[8]}$. 2-Nitro-3-(4nitro-phenyl)-cyclopropane-1,1-dicarbonitrile(7) ${ }^{[9]}$

The structures of the intermediate and representative compounds were shown in Fig. 1

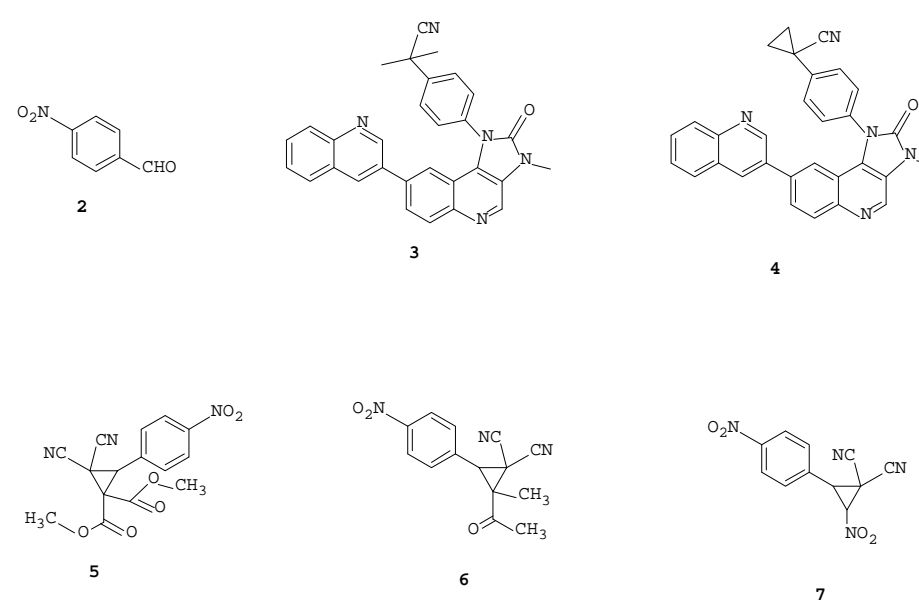

Fig.1 Structures of the intermediate and some drugs that have been reported

\section{MATERIALS AND METHODS}

The Melting point(M.P) of compounds was taken by $\mathrm{X}-4$ type digital melting point apparatus manufactured by Beijing Tektronix, Inc. (temperature Degree without more positive).Mass spectra (MS) were taken in ESI mode on Agilent 1100 LC-MS. H NMR was taken by a Bruker ARX-300 NMR analyzer. TLC analysis was carried out on silica gel platesGF254 (Qin dao Hai yang Chemical, China).All the materials were obtained from commercial suppliers and used without purification, unless otherwise specified. 


\section{SYNTHESIS OF COMPOUNDS}

The structures and the synthetic route were shown in Scheme 1

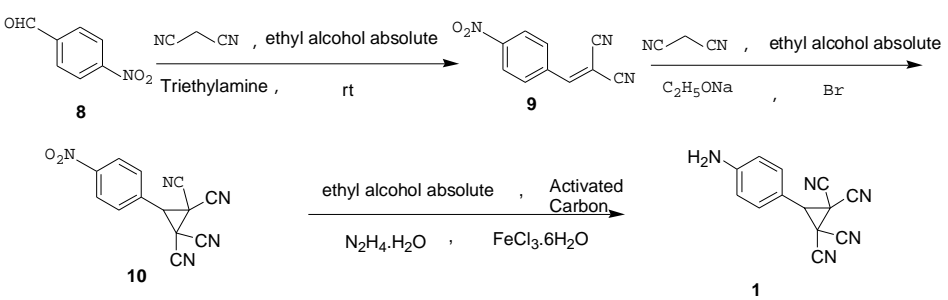

Scheme1. The synthetic route of compound 1

Reagents and conditions: (a) Triethylamine, ethyl alcohol absolute, rt, 4 h; (b) ethyl alcohol absolute, $\mathrm{C}_{2} \mathrm{H}_{5} \mathrm{ONa}$, Bromine; (c)ethyl alcohol absolute, $\mathrm{FeCl}_{3} \bullet 6 \mathrm{H}_{2} \mathrm{O}, \mathrm{N}_{2} \mathrm{H}_{4} \bullet \mathrm{H}_{2} \mathrm{O}$, Activated Carbon.

\subsection{2-(4-nitrobenzylidene)malononitrile (9)}

Malononitrile was dissolved in $\mathrm{C}_{2} \mathrm{H}_{5} \mathrm{OH}(10 \mathrm{~mL})$, then it was added drop-wise to 4-nitrobenzaldehyde ( $3.0 \mathrm{~g}, 0.02 \mathrm{~mol}$ ) suspension at room temperature, control the drip rate and the temperature was kept 25 $\sim 27{ }^{\circ} \mathrm{C}$. When the addition was complete, the triethylamine $(0.033 \mathrm{~mL}, 0.25 \mathrm{nmol})$ was added under stirring, and keep the reaction at room temperature for $4 \mathrm{~h}$, After the reaction completed, the mixture was filtered off, washed with EtOH, and dried under reduced pressure to afford 2-( 4- nitrobenzylidene ) malononitrile(3) as yellow solid(4.0g, 93\% ). ${ }^{1} \mathrm{H}$ NMR (400 MHz, DMSO) $\delta 8.26(\mathrm{~d}, J=8.8 \mathrm{~Hz}, 2 \mathrm{H})$, $8.12(\mathrm{~s}, 1 \mathrm{H}), 8.09$ (d, $J=8.8 \mathrm{~Hz}, 2 \mathrm{H})$. M.p.163$168^{\circ} \mathrm{C}$, MS: $200.1[\mathrm{M}+\mathrm{H}]^{+}$

\subsection{3-(4-nitrophenyl)cyclopropane-1,1,2,2- tetracarbonitrile(10)}

2-(4-nitrobenzylidene) malononitrile (2) $(0.185 \mathrm{~g}$, $0.001 \mathrm{~mol})(20 \mathrm{~mL})$ was dissolved in $\mathrm{C}_{2} \mathrm{H}_{5} \mathrm{OH}$ $(20 \mathrm{~mL})$, then the solution of $\mathrm{C}_{2} \mathrm{H}_{5} \mathrm{ONa}(0.0012 \mathrm{~mol})$ was added under stirring for $1 \mathrm{~min}$ and the bromine was added without cooling. The mixture was magnetically stirred at room temperature. After stirring for $6 \mathrm{~h}$ at r.t, the reaction was completed. The solid phase was filtered off, washed with warm water, and dried in desicator over $\mathrm{P}_{2} \mathrm{O}_{5}$ to isolate pure white solid $(0.2 \mathrm{~g}, 87 \%) .{ }^{1} \mathrm{HNMR}\left(400 \mathrm{MHz}, \mathrm{CDCl}_{3}\right)$ $\delta 8.19(\mathrm{~d}, J=8.8 \mathrm{~Hz}, 2 \mathrm{H}), 7.45(\mathrm{~d}, J=8.8 \mathrm{~Hz}, 2 \mathrm{H}), 1.7$ (S,1H). M.p. $232-235^{\circ} \mathrm{C}, \mathrm{MS}: 234.0[\mathrm{M}+\mathrm{H}]^{+}$

\subsection{3-(4-aminophenyl) cyclopropane-1, 1, 2, 2- tetracarbonitrile $(1)$}

3-(4-nitrophenyl)cyclopropane-1,1,2,2-

tetracarbonitrile $(0.2 \mathrm{~g}, 0.0008 \mathrm{~mol})$ was dissolved in anhydrous ethanol and heated to $60^{\circ} \mathrm{C}$, then activat- ed carbon $(1 \mathrm{~g})$ and $\mathrm{FeCl}_{3} \cdot 6 \mathrm{H}_{2} \mathrm{O}(0.43 \mathrm{~g})$ was added into the solution, $0.25 \mathrm{~mL} \mathrm{~N}_{2} \mathrm{H}_{4} \cdot \mathrm{H}_{2} \mathrm{O}$ was added and reflux for $2 \mathrm{~h}$. After the reaction completed. Then the mixture was hot filtrated. The filtrate was distilled under reduced pressure to afford $\mathbf{1}$ as yellow solid (65.25\%). ${ }^{1} \mathrm{HNMR} \quad(400 \mathrm{MHz}, \quad \mathrm{DMSO}) \quad \delta$ $6.84(\mathrm{~d}, J=8.9 \mathrm{~Hz}, 2 \mathrm{H}), \delta 6.32(\mathrm{~d}, J=8.9 \mathrm{~Hz}, 2 \mathrm{H})$, 4.3(s,1H),1.7(s,H). M.p.192-196 ${ }^{\circ} \mathrm{C} \quad$,MS:263.0 $[\mathrm{M}+\mathrm{H}]^{+}$

\section{CONCLUSIONS}

In conclusion, 3-(4-aminophenyl) cyclopropane-1, 1, 2, 2-tetracarbonitrile was synthesized from the commercially available 4-nitrobenzaldehyde through three steps. The synthetic method of compound $\mathbf{1}$ and the reactions conditions were optimized. Its structure was confirmed by MS and ${ }^{1} \mathrm{HNMR}$ spectrum.

\section{ACKNOWLEDGMENTS}

We gratefully acknowledge the generous support provided by The National Natural Science Funds (No. 81460527), Science and Technology Project of Jiangxi Science \& Technology Normal University (2014XJYB002), Science and Technology Project Founded by the Education Department of Jiangxi Province (No. GJJ150796), Program of Key Laboratory of Drug Design and Optimization, Jiangxi Science \& Technology Normal University(300098010306), College Students' Science and Technology Innovation Project of Jiangxi Province and the Innovation Fund Designated for Graduate Students of Jiangxi Province (YC2015-X28).

\section{REFERENCES}

[1] Network T C G A. Integrated genomic analyses of ovarian carcinoma. [J]. Nature, 2011, 474 (7353): 609- 615.

[2] Han, Fangbin, et al. Synthesis and structure-activity relationships of PI3K/mTOR dual inhibitors from a series of 2amino-4-methylpyrido [2, 3-d] pyrimidine derivatives. J. Bioorganic \& medicinal chemistry letters, 24.18 (2014) 4538-4541.

[3] Zhu, Wufu, et al. Design, synthesis, anticancer activity and docking studies of novel 4-morpholino-7, 8-dihydro-5Hthiopyrano [4, 3-d] pyrimidine derivatives as mTOR inhibitors. J. Bioorganic \& medicinal chemistry, 22.24 (2014) 6746-6754.

[4] Zhu W, Wang W, Xu S, Wang J, Tang Q, \& Wu C, et al. (2016). Synthesis, and docking studies of phenylpyrimidinecarboxamide derivatives bearing 1h-pyrrolo [2,3-b] pyridine moiety as c-met inhibitors..Bioorganic \& Medicinal Chemistry, 24(8), 1749-1756.

[5] Qiao Y, Zhao J, Lee P, et al. Cell killing efficacy of combined electroporation and drug delivery of NVP-BEZ235[J]. 
Journal of Vascular \& Interventional Radiology, 2015, 26(2).

[6] Cerniglia G J, Jayashree K, Sonia T, et al. Inhibition of autophagy as a strategy to augment radiosensitization by the dual phosphatidylinositol 3-kinase/mammalian target of rapamycin inhibitor NVP-BEZ235. [J]. Molecular Pharmacology, 2012, 82(6): 1230-40.

[7] Elinson M N, Feducovich S K, Zaimovskaya T A, et al. Electrocatalytic transformation of dialkyl malonates and arylidene-or alkylidenemalononitriles into dialkyl esters of 3substituted 2, 2-dicyanocyclopropane-1, 1-dicarboxylic acids[J]. Russian chemical bulletin, 2005, 54(7): 1593-1598.

[8] Ducray P, Bouvier J. Pharmaceutical composition containing aminocetonitrile compounds and the use thereof for the preparation of a pharmaceutical composition for the treatment of endoparasitic pests in animals: US, US7063856[P]. 2006.

[9] Li. J, Liu. Y. C, Deng J. G. . Asymmetric reduction of 2bromo-1-phenylethylidenemalononitrile with chiral NAD(P)H models[J]. Tetrahedron Asymmetry, 1999, 10(22):4343-4347. 